\title{
Scoping Review of Crimean-Congo Hemorrhagic Fever (CCHF) Literature and Implications of Future Research
}

\author{
Braira Wahid1, Saba Altaf1, Nabiha Naeem¹, Nimra Ilyas1 and Muhammad Idrees2
}

\begin{abstract}
Crimean-Congo hemorrhagic fever (CCHF) is one of the severe forms of high-fatality hemorrhagic fever transmitted by bite of infected ticks or body fluids of infected individuals. Lack of sufficient research and endemic potential of the disease is posing serious threats to public health. The aim of this review was to explore the current status of Crimean-Congo hemorrhagic fever virus (CCHFV) related research and to identify knowledge gaps and the areas that are yet to be explored. An interpretative scoping review methodology was followed to systematically characterize the most recent literature. Literature survey was conducted using electronic databases: PubMed, Scopus, ScienceDirect and Google Scholar. This comprehensive research yielded more than 300 records, but we excluded 100 articles based on our inclusion criteria and duplicates removal. All articles $(n=85)$ that have been published currently were discussed in this scoping review. From a total of 303 documents retrieved, 85 met the criteria. All the documents (case studies, review articles, systematic reviews, meta-analysis, case control studies, cohort studies, randomised control trials, and longitudinal studies) were included in the study. The articles mainly cover different areas such as epidemiology, prevalence, diagnosis, pathogenesis, clinical outcomes, molecular basis, phylogenetics, transmission and treatment of CCHF. Treatment and prevention related knowledge is limited; therefore, future research should focus the development of therapeutics to mitigate the increasing risk of CCHF. Priority future goal should be studies on the molecular basis and treatment of CCHFV infection because several knowledge gaps have been identified in these areas.
\end{abstract}

Key Words: CCHF, CCHFV, Molecular basis, Pathogenesis, Treatment, Phylogenetics.

\section{INTRODUCTION}

This disease is widely distributed all across the Globe, specifically Asia, Middle East, and Africa. Crimean-Congo hemorrhagic fever virus (CCHFV) infection is easily transmissible, highly pathogenic and causes CrimeanCongo hemorrhagic fever (CCHF) which has fatality rate of $>40 \% .1,2$ The incidence of CCHFV has been increasing since $2008 .{ }^{3}$ Different aspects of CCHFV are described below:

History: CCHFV was first recognised in Tajikistan in the $12^{\text {th }}$ Century. In 1944, the evidence of CCHF was reported from the Crimean region of the former Soviet Union, followed by several other cases reported in several southern Soviet Republics, South Africa and Bulgaria during next few decades. The virus derived its current name 'Crimean-Congo hemorrhagic fever' because same disease was reported in 1969 in Congo region. 4

Since 2000, small outbreaks of CCHFV have documented in Greece, India, some Balkan countries, Pakistan, Turkey, Spain, Sudan, Uganda, Georgia, and Iran. Since

${ }^{1}$ Department of Life Sciences, School of Science, University of Management and Technology, Lahore, Pakistan

${ }^{2}$ Hazara University, Mansehra, Pakistan

Correspondence: Prof. Muhammad Idrees, Hazara University, Mansehra, Pakistan

E-mail: idrees.khan96@yahoo.com

Received: April 28, 2018; Accepted: November 27, 2018
August 2016, an increased incidence of CCHFV has been reported in Pakistan.5,6

Structure, genome organisation, classification, and molecular biology of virus: CCHFV is a tick-borne disease that belongs to family Bunyaviridae and genus Nairo virus that includes four others: genera Tospo virus, Phlebo virus, Hanta virus, and Orthobunya virus. The L-segment of Nairo virus makes them different from rest of Bunya viruses. Out of seven known serogroups, the CCHF serogroup includes Hazara virus (HAZV) and CCHFV. HAZV was first isolated from Pakistan.7,8

The CCHFV is spherical in shape with diameter about 80-100 nm, glycoprotein spikes are 8-10 nm in length and lipid envelope is 5-7 nm thick. The genome is composed of negative ssRNA that is divided into three segments: L-segment that encodes $\sim 450 \mathrm{kDa}-\mathrm{RNA}$ dependent RNA polymerase (L-RdRp), M segment encodes $\sim 1700$ amino acid precursor that leads to production of viral glycoprotein consisting of mature Gc (75-kDa) and $\mathrm{Gn}(37-\mathrm{kDa})$ proteins, and $S$ segment encodes nucleocapsid protein. ${ }^{9}$ Reverse genetic system of CCHFV has been developed to better understand the virus biology and to develop therapeutic measures against CCHFV. 10

In CCHFV, Gc acts as primary target-binding protein and mediates virus entry through $\mathrm{pH}$ and cholesterol dependent clathrin-dependent endocytosis that determines association between CCHFV distribution in human tissues and cell-surface expression of nucleolin. After attachment of virus to cell-surface receptors, followed by 
entry through endocytosis, RdRp access the cytoplasm. RNA replication, translation, and trans-cription leading to production of viral proteins. Virus particle assembles at Golgi membrane, then, the new CCHFV virus particle buds off from host cell membrane and enters another cell. $11-13$

Transmission: CCHFV is transmitted through ticks, specifically belonging to genus Hyalomma. ${ }^{14}$ CCHFV has been isolated from one species of biting midge and about 31 species of ticks of which two species belongs to family Argasidae (soft ticks). Another study reported that atleast 28 species of Ixodid ticks are the member of seven genera (Haemaphysalis, Ambylomma, Boophilus, Ixodes, Rhipicephalus, Hyalomma, and Dermacentor) of the family Ixodidae (hard ticks). ${ }^{15}$ CCHFV is easily transmitted from one area to another because of migration of infected livestock population. ${ }^{16}$ Accumulating evidence suggests the vertical and horizontal transmission of CCHFV.

Vertical transmission: Tick vectors of CCHFV show the transfer of virus from adult females to males during fertilisation and from adult females to their eggs. CCHFV replicates in the mid-gut lining if ticks and spread to different body tissues such as salivary glands and reproductive organs. A large population of infected ticks is maintained because of transovarian transmission via thousands of eggs produced by females.

Horizontal transmission: Virus gains entry into human body through tick's bite or via direct contact with infected animal blood (veterinarians, slaughter house workers, and farmers etc.). Person-to-person transmission through different body fluids specifically blood, semen, and saliva has been observed. 17 Three cases of sexual transmission among spouses have been documented recently. 18

Phylogenetics and genetic diversity: Phylogenetic analysis of $L$ and S-RNA segments of CCHFV revealed seven different genetic clades based on geographical regions: two Asian, two European, and three African. ${ }^{19}$ Eight different clades are shown in Table I, based on outbreaks that has been reported in Iraq, USA, Pakistan, Saudia Arabia, Bulgaria, Turkey, India, Democratic Republic of the Congo, Uganda, and Mauritania during the recent years. 20

Table I: Geographical distribution of eight different clades of CCHFV.

\begin{tabular}{l|c|c}
\hline Geographical origin & Clades & Reference \\
\hline Uganda & 1 & {$[21]$} \\
\hline Central African Republic and Nigeria & 2 & {$[21]$} \\
\hline South Africa, Mauritania, Senegal & 3 & {$[21]$} \\
\hline Turkish, Southeast Russian, and European strains & 4 & {$[22-24]$} \\
\hline Central Asia, China, Uzbekistan, Tajikistan, Kazakhastan & 5 & {$[25]$} \\
\hline Greece (A92 isolated from Riphicephalus bursa) & 6 & {$[22,23]$} \\
\hline Group 1 (Iran, Pakistan and Madagascar) & 7 & {$[22]$} \\
\hline Group 2 (Iran, Mauritania, and Senegal) & 8 & {$[22]$} \\
\hline
\end{tabular}

The study also traced the ancestral origin of all clades 1000 years back, possibly in Africa. CCHFV migrated to Middle East and then travelled in two directions leading to two Asian clades; first on scattering in Central Asia and China, while the second one in Pakistan and Iran. Two highly divergent strains that were assumed Turkish invaded Europe finally. Figure 1 shows the genetic diversity of several different strain of CCHFV belonging to different regions of the world, based on phylogenetic analysis of sequence data of S-RNA segment. The genetic analysis of M-segment indicated phylogenetically distinct groups in China, Russia, and Tajikistan.26-28

Figure 1 shows phylogenetic tree constructed by MEGA5 software based on a small segment of CCHFV. Bootstrap values in percentages (of 1000 replicates) are mentioned above branches. Red highlighted strains indicate reassortment and green highlighted strains indicate recombination. ${ }^{28}$

According to different phylogenetic studies, the recombination occurs in short genome regions of S-segment only. CCHFV strains that undergo recombination are Drosdov, TI10145 from Uzbekistan; Kashmanov, HY-13 from China; JD206 from Pakistan; and STV/HU29223 from Russia.4,29,30

Pathogenesis: Very little is known about the pathogenesis of CCHF. The most significant feature of pathogenesis is the ability of CCHFV to disable immune system of host and immune cells as well as endothelial cells (EC) are the key contributors. Virus either interacts with immune cells indirectly concomitant with the release of mediators or interacts with ECs directly. The upregulation of proinflammatory cytokines and soluble molecules activate ECs, which in severe cases may produce toxic effects vasodilation, hypotension, increased vascular permeability, shock, multiple organ failure, and death. Several studies exhibit that clearance of CCHFV is delayed. CCHFV impairs innate immune response and delays adaptive immune system and cause systematic spread as well as uncontrolled replication of virus throughout host body accompanied with the delayed induction of interferon, increased level of IL-6, IL-1, TNF-alpha, apoptosis of lymphocytes, partial activation of macrophages and dendritic cells, lymphohistiocytosis, hemophagocytosis, and weak antibody response. ${ }^{12,31-37}$

Clinical features: During prehemorrhagic period, patients experience fever, chills, polyneuritis, abdominal pain, back pain, loss of appetite, poor vision, vomiting, nausea, labored breathing, diarrhea, loss of hearing, and loss of memory. Several cardiovascular as well as neuropsychiatric changes such as mood swings, confusion, violent behaviour, and aggression have also been reported. Hemorrhage, dehydration, anemia, myocardial infarction, pleural effusion, kidney failure, lung edema, capillary fragility, thrombocytopenia, capillary toxicosis occurs in severe cases of CCHF.31,38-41 
Diagnosis: Early diagnosis as well as differential diagnosis is necessary for prevention of CCHF. Recent development of novel one-step rRT-PCR assay is emerging as sensitive, specific, simple, reliable, rapid, and repeatable tool for the detection of the CCHFV RNA that is detectable until day 16 of illness. 42 Immunoflourescence assay and antigen-capture ELISA based on recombinant viral $\mathrm{N}$ protein can detect viral antigens, or virus specific IgM and IgG antibodies that can be detected by the fourth month of illness and by six day, respectively. Cell culture technique is applicable only for the first five days of illness.

Treatment: Supportive therapy including the administration of erythrocytes, thrombocytes, and fresh frozen plasma acts as an important strategy to control CCHF at an early stage. Ribavirin acts as an effective anti-viral agent against CCHFV by inhibiting its replication. $43 \mathrm{~A}$ recent study has demonstrated the synergistic effect of combination of two FDA approved molecules i.e., chloroquine or chlorpromazine and ribavirin against CCHFV. 44 Another novel molecule MxA belonging to interferoninduced GTPases family and dynamin superfamily inhibited CCHFV production and replication. 45 DNA vaccination expressing $G c$ genes and $G n$ elicited neutralizing antibodies in mice; however, the efficacy in humans is still to be determined. 46,47

Global epidemiology and prevalence in Pakistan: Recent study revealed that CCHF is endemic in 47 countries including Asia, Africa, Middle East, and Europe. The more focalised areas of risk encompass various regions of South East Asia, Sub-Saharan Africa, Sahel, Cape region, Black Sea, and Central Asia. 48

In Pakistan, three different outbreaks were recorded in 1976,1994 , and 2000. A total of 161 confirmed cases were confirmed during 2012 to 2015, and 45 deaths were reported from 2012 to July 2014. The infection is increasing sporadically in Pakistan because death toll has climbed to 19 during the year 2016 (Table I).49,50

Phylogenetic analysis revealed that CCHFV strains found in Pakistan belong to genotype Asia-1 that include four distinct subclades. Strains found in Pakistan showed $90-100 \%$ similarity with Iranian and Afghani strains. New subclade-D includes six strains of CCHFV reported in Afghanistan and Pakistan.6,16 Eid-ul-Adha would increase the risk of transmission of CCHFV because about 5 million animals are slaughtered annually in Pakistan. Therefore, government should start awareness campaigns regarding the practice of personal protective measures so that life loss can be avoided.

\section{METHODOLOGY}

All authors conducted electronic search to identify articles published since the start of 2016 on PubMed,
Scopus, ScienceDirect, and GoogleScholar. Different keywords were used for literature survey such as: CCHF epidemiology, CCHF prevalence, CCHF pathogenesis, CCHFV virology, CCHF treatment, prevention, diagnosis, and therapeutics, phylogenetics, molecular basis etc. No language restrictions were used during primary search. All records were thoroughly studied to identify eligibility and relevance prior to duplicates removal (Figure 2).

Eligible publications included all observational studies (cross-sectional studies, longitudinal studies, case-control studies, case-cohort studies), experimental studies, descriptive studies, case-reports, editorials, mathematical models, literature reviews, systematic reviews, and meta-analysis which have been published since first January 2015 to date.

All authors independently screened abstracts, article titles and year of publications to select records for fulltext read. Then, we assessed full-texts of articles and consulted other reviewers in case of disagreements so that final decision can be made with mutual consensus. Eighty-five articles were finally selected and used spreadsheet to record information such as authors, study area, study design, methods, key findings, and conclusion.

\section{RESULTS}

There are limited sources describing the global burden of emerging diseases. CCHFV infections reported by ProMED were reviewed and the reliability of the data retrieved was assessed compared to published reports. The effectiveness of ProMED as a source of epidemiological data was evaluated by focusing on CCHFV infections.

Transmission related studies: Studies related to transmission showed that in Ghana, ticks collected from cattle positive for CCHFV belonged to genera Hyalomma, Ambylomma, and Boophilus. ${ }^{14}$ In Dadra and Nagar Haveli, and India, ticks collected from domestic mammals belong to three different species of Hyalomma i.e, Hyal. anatolicum anatolicum, Hyal. detritum, and Hyal. marginatum isaaci.51 In Asia, Africa, and Europe, 12 people out of total $21 \mathrm{CCHFV}$ positive travellers were died who travelled between Asia, Europe and Africa. 52 About $38.2 \%$ of goats were found positive for CCHFV while none of cattle gave positive results in Bhutan. ${ }^{53}$ In Spain and Morocco, CCHFV and Rickettsia were confirmed in Hyalomma spp. ticks specifically Hyalomma Marginatum isolated from migratory birds that carried infected ticks from Morocco to Iberian Peninsula. ${ }^{54}$ In Great Britian, 12 Hyalomma ticks were recovered from migratory birds but they were negative for CCHFV. ${ }^{55}$

In Congo, Gabon, Ghana, Germany, and Panama, reactive antibodies were confirmed in $10.0 \%$ of bats belonging to 12 of 16 species of bats. About $0.6 \%-7.1 \%$ of foliage-living bats and $3.6 \%-42.9 \%$ of cave-dwelling 
bats were seropositive. Neutralising activity in a virus like particle assay was exhibited by 11 of 30 IIFTreactive sera belonging to 10 different African bat. Neutralisation of full CCHFV was confirmed in 5 of 7 sera. 56

Sexual transmission of CCHFV among spouses was confirmed in Salsk. ${ }^{57}$ In Mazandaran, Iran, novel strain that was different from all other strains of CCHFV but closely related to AP-92 was confirmed in patient. ${ }^{57}$ Seroprevalence rates for CCHFV were lower in cattle than in goats and sheeps in Albania and former Yugoslav. 58 In Bulgaria and Turkey, up to $90 \%$ prevalence (Turkey $57 \%$ and Bulgaria $26 \%$ ) was identified in sera of
1,165 ruminants. 59 In Northeast of Iran, CCHFV has been shown to transmit via direct contact with infected tissue or blood of livestock. 60

Epidemiology and surveillance: An alarming rise in cases of CCHFV has been noticed since 2000 with 50-60 cases reported annually. Severe outbreak was reported in 2012 with $61 \%$ suspected cases and $27.8 \%$ casefatality rate in Pakistan. Total international prevalence varies between $0-30.68 \%$ in camel, cattles, chicken, buffalo, ostrich, pig, goats, horses, mules, and donkeys. ${ }^{61}$ Eighty-one cases were reported during 1999-2015 and most deaths were reported in 2003. About $95 \%$ patients experienced thrombocytopenia, bleeding and fever in

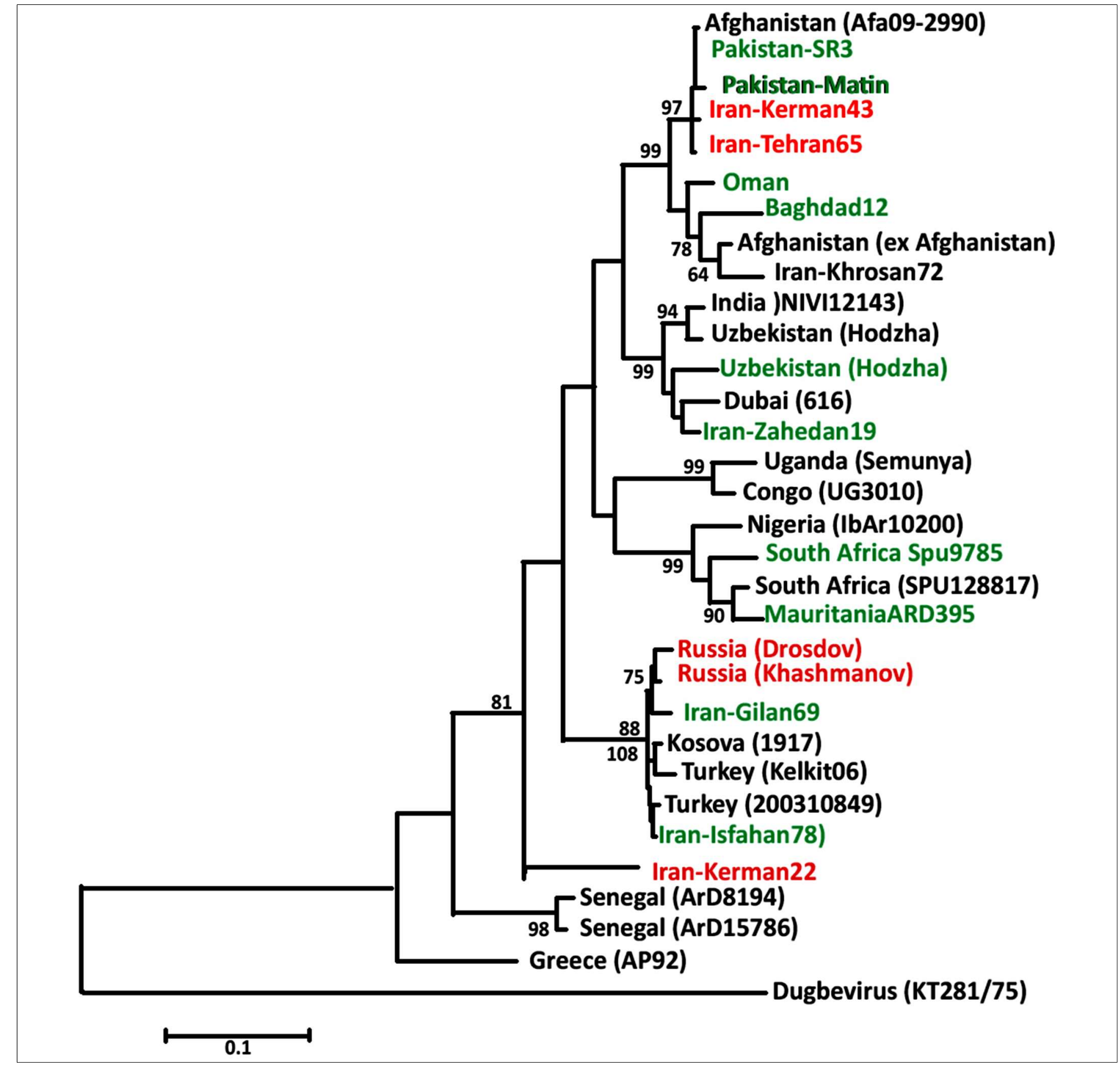

Figure 1: Phylogenetic tree constructed by MEGA5 software based on a small segment of CCHFV. Bootstrap values in percentages (of 1000 replicates) are mentioned in above branches. Red highlighted strains indicate reassortment and green highlighted strains indicate recombination. 28 


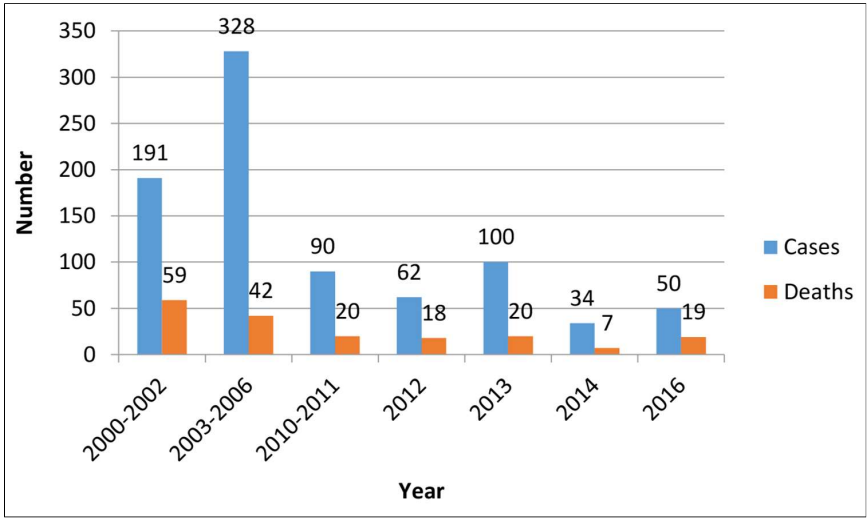

Figure 2: Reported CCHF cases and deaths since 2000.

Khuzestan.62 Significant increase in number of clinical cases of CCHF in southeastern Europe has been observed after 2000.63 Majority of ticks that were collected from birds and horses belong to Hyalomma species especially of $H$. marginatum. 64 In Djibouti, alkhumra virus and CCHFV were confirmed among 2 (infection rate $=0.2$ per $100,95 \% \mathrm{Cl}: 0.0-0.7$ ) tick pools from $2(1 \%)$ cattle and 141 (infection rate=15.7 per 100, 95\% Cl: $13.4-18.1)$ tick pools from $81(37 \%)$ cattle. 65 In Manisa, IgG antibodies were identified in about $15 \%$ of samples. Highest seroprevalence was found to be $7.1 \%$ for $F$. tularensis. Distribution of the positive results were $0.9 \%, 3.7 \%$, and $4.3 \%$ B. burgdorferi, CCHFV, and WNV, respectively. 66

The percentage of tick related seroprevalence was $3 \%$ that was higher than previously detected seroprevalence $(0.03 \%)$. About $49 \%$ of infected individuals were males and median age was 54.8 years. $67 \mathrm{CCHFV}$ genome was detected in 49 of total 480 ticks. CCHFV-specific IgG antibodies in 6 of 11 cities. 9 of total 171 humped camels were IgG positive, East and Northeast of Iran.68 In Pakistan, 14 outbreaks were documented during 19762010. Significant increase has been reported during recent years. 69 Turkey is endemic for both CCHF and brucellosis and differential diagnosis is necessary for distinguish both infections. ${ }^{70}$ In Tunisia, Hyalomma scupense ticks were found in Mabtouh. H. dromedarii was found in Daghounes and Sidi Toui. RT-PCR was negative for CCHFV. In Tunisia, IgG anti-CCHFV was detected in 2 of total 38 slaughter workers exhibiting $5.2 \%$ seropravelence. ${ }^{71}$

In Van province, Turkey, CCHF-IgM seropositivity was found to be $3.7 \%$ and CCHF-IgG seropositivity was $14.4 \%$. Yet, no death has reported in Van. ${ }^{72}$ Sixty-two percent of participants of study lived outside Afghanistan. Antibody prevalence for VL, CCHF, and DENV was found to be $8 \%, 33 \%$, and $17 \%$, respectively. ${ }^{73}$

Mortality rate was found to be $11.1 \%$ and the mean viral load in dead and survived patients was $4.6 \times 109$ copy $/ \mathrm{ml}$ and $8.3 \times 10^{7}$ copy $/ \mathrm{ml}$, respectively. ${ }^{74}$ In Turkey, the first case of CCHF was reported in 2002, since then 9700 cases have been documented. Overall mortality rate is below $5 \% .75$

In Kedougou, no patient was tested positive for $\mathrm{CCHF}$ and WNF.76 In Mali, IgM seroprevalence was documented in $7.7 \%, 5.3 \%, 0.27 \%$, and $7.2 \%$ in DENV, CHIKV, WNV, and $\mathrm{CCHFV} .76$ Individuals who were exposed to livestock were more likely to test positive for CCHFV IgG. 77

Treatment, diagnosis, and prevention: Bleeding or endothelial injury is an important factor of CCHF pathogenesis and TGF- $\beta 1$ repairs injured endothelium. The decrease level of TGF- $\beta 1$ highlighted its importance as prognostic and diagnostic biomarker of bleeding in CCHF patients. ${ }^{78}$

Clinical findings proved that severity of disease can be determined by platelet distribution width. 79 Cytokines, cell adhesion molecules, peripheral natural killer cells, mannan binding lectin, circulating plasma cell-free DNA, CUBE1, thrombin level, albumin level, CD3+, CD8+ T cells, CD14 serve as prognostic or diagnostic biomarker to determine severity and fatility of CCHF.80 In Iran, 42 of total 75 suspected serum samples were positive for CCHFV.42 Significant increase in concentration of HMBG1 was observed in patients of CCHFV. ${ }^{81}$

According to another retrospective controlled study, increased total oxidant status, decreased total antioxidant status, and increased disulfide/native thiol and disulfide/total thiol ratios was observed in patients with CCHF. 82

Infectivity of Hazara virus was decreased because of over-expression of AQP6. These results highlighted the protective role of APQ6.83 Tranexamic acid was effective hemorrhagic conditions. 84 In Ankara, Turkey, patients receiving ribavirin did not show significant difference in mortality, recovery time, and hospital stay. 43 The specificity, sensitivity, negative predictive value, positive predictive value for predicting mortality was found to be $72 \%, 100 \%, 100 \%$, and $79 \% .85$

In Turkey, CCHFV RNA was not the discharge criteria patients were discharged based on resolving symptoms and fever with no bleeding. ${ }^{86} \mathrm{An}$ increase in serum level of BD2 was observed in CCHF patients. ${ }^{87}$

Level of $\mathrm{P}-10$, and MCP-1, was different between severe and non-severe survivors of CCHF. Likewise, significant difference in levels of TNF- $\alpha$, MCP-1, IP-10, IL-15, IL-10, IL-9, IL-8, IL-6, IL-5, L-1b, RANTES was observed between fatal and non-fatal patients. 88 Decrease in monocyte and lymphocyte levels, and increase in neutrophil levels were the risk factors of mortality. 89

Clinical outcome: During the three-day admission in hospital, decrease in creatinine, CPK, INR, PT, aPTT, haemoglobin levels and increase in leukocyte count was significant in non-fatal cases. 90 Of 11 deaths, 4 occurred in group 1; and 7 occurred in group 2.91 
The average diameter of pulmonary artery of study group was significantly larger than the control group. 92 Body pain, fever, headache, nausea, vomiting, leucopenia, thrombocytopenia, fatigue, elevation of alanine transaminase (ALT), aspartate aminotransferase (AST), lactate dehydogenase ( $\mathrm{LDH})$ were observed in $\mathrm{CCHF}$ patients. 38

In Turkey, the patient was initially diagnosed with CCHF but endocardititis was confirmed during later on stages. 93 In Mauritinia, in response to supportive therapy and platelet transfusion, epistaxis and hemorrhagic like conditions improved on the third day of hospitalization whereas, CT showed acute subdural hematoma. 94

Molecular: Nineteen of the total 106 differentially expressed miRNAs were either 5-fold significantly downor upregulated. DENV and Hanta virus associated miRNAs were also discovered. WNT, MAPK, TGF-beta, TNF-alpha, neutrotrophic siganlling pathways are associated with CCHF infections. ${ }^{95}$ Chaperones of the HSP70 family is necessary for nairovirus replication and prevent nairovirus mediated disease by acting as genetically stable potent target for anti-nairoviral therapies. The results showed that nucleocapsid protein of Hazara virus and related CCHFV interact with HSP70 during viral life cycle. 96

OTU defective or inactive mutants may be potential vaccine candidates because OTU domain plays key role in CCHFV-mediated innate immunity by selectively cleaving ubiquitin or ISG15 conjugates. 97 One crosssectional cohort study from Turkey, reported CCHF severity grading score (SGS) with high intermediate risk score (10 out of 20 ) and low risk scores (10 out of 20 ) for mortality. Five of the total 20 patients had fatal outcome. Anti-apoptotic and pro-apoptotic gene expression modulates apoptosis in CCHF patients. 98

CCHFV reverse genetics systems such as minigenome system and virus-like particle system, and infectious clone system helps in study of underlying mechanisms of viral replication, translation, transcription, particle assembly, egress, mutational analysis, mechanism of viral drug resistance, cell mediated host response, OTU domain activity and viral protein function. CCHFV glycoprotein and nucleoprotein functions are the critical areas of research to understand replication cycle and differences in genotypes, respectively. ${ }^{99}$

In Iran, S-segmant of genome of different strains switch and recombine leading to diversification of CCHFV. 100

In Khuzdar Cantt Pakistan, HLAA*2601, 2402, 0301, 0201 , 0101, B*1501, 5801, 4001, 3901, 2705, 0801, 0702 against 2 glycoproteins of CCHFV were observed. Total 35 and 5 nanomers were identified in GP1 and GP2, respectively. The strongest binding affinity was displayed by HLA B* 4001 and HLA B*0702 bound maximum number of peptides. ${ }^{101}$ About $9 \%$ ticks (i.e, Hyalomma anatolicum, Hyalomma marginatum, and Rhipicephalus sanguineus) were positive for CCHFV that belonged to Matin and SR3 strains of Pakistan and Iran. 102

Phylogenetics: Phylogenetic tree revealed the similarity of strain with Iran, Afghanistan, and Pakistan strains but different from the strains previously reported in India.103 Low genetic differences were observed among CCHFV strains. The maximum genetic difference observed was $0-6 \%$ in $M$ segment. These results shows the slow evolution of CCHFV strain in Bulgaria. 16S rDNA sequence of $H$. rufipes from Germany and Tanzania was identical. Tick was tested negative for CCHFV. 104 About $5.2 \%$ of ticks specifically Haemaphysalis, Rhipicephalus, and Hyalomma were positive for CCHFV in Golpayegan, Isfahan, Iran. 10539 of 623 Hyalomma marginatum ticks belonged to CCHFV lineage Europe 1 and 49 of 415 Rhipicephalus sanguineus sensu lato ticks were associated with Europe 2 Bulgaria.106 Partial S segment phylogeny placed $4 \%, 14 \%$, and $80 \%$ Iranian strains in clade IV(Asia 2), clade IV-(Asia 1), and clade V-(Europe). Phylogenetic analysis of partial $M$ segment revealed that Iranian strain belongs to clade V (Europe) or clade III (Asia-Africa). One Iranian strain i.e., Iran-Kerman/22 was associated with new clade VII as it was different from all other sequences. 107 In Japan, Tofla virus is closely associated with Hazara virus and belongs to CCHFV group. ${ }^{108}$ About $28.6 \%$ were positive for CCHFV. Fifteen sequences that were identified as CCHFV was $98 \%-100 \%$ identical to AP92 strain. Two variants of AP92 were detected and differed by $0.6 \%$. AP92-like sequences was related to $H$. aegyptium ticks and Europe 2 lineage in Algeria was reported. 109

Pathogenesis: Severity grading score classified CCHF patients into three categories: mild group (1204.53 $\pm 371.18)$, moderate group (1464.21 \pm 338.37$)$, and severe group (2007.36 \pm 82.18$)$. Presepsin level increases with increase in severity of disease.110 TLR3 SNPs were identified in patients of CCHF. Genotypic frequency of TLR3 (c.1377C/T and $-7 \mathrm{~A} / \mathrm{C}$ ) of fatal cases was comparable to non-fatal cases. genotypic frequency of homozygous mutant (TT) TLR3 c.1377C/T was found to be higher in CCHF patients in Sivas/Turkey. ${ }^{111}$ SNPs that played an important role in CCHF susceptibility were IFNA17 rs9298814 and IFNA1 rs1332190. ${ }^{112}$

The titer of the pseudotyped VSV was increased by partial deletion of the CCHFV GP cytoplasmic domain and DC-SIGN (a calcium-dependent [C-type] lectin cellsurface is an important factor for entry of CCHFV. ${ }^{113}$

Serum level of sTREM-1 $>405.9 ? \mathrm{pg} / \mathrm{ml}$ existed as a cut off point to distinguish healthy individuals from $\mathrm{CCHF}$ patients with $87.5 \%$ specificity and $94.9 \%$ sensitivity. 114 Results exhibited degradation of CCHFV NSs during infection. Ectopic expression of CCHFV NSs induces apoptosis using Leu-127 and Leu-135 as key residues. 
CCHFV NSs and Leu-127 and Leu-135 also play an important role in disruption of mitochondrial membrane. ${ }^{115}$ Threshhold criteria Rth $>1$ indicates asymptotically stable endemic equilibrium in the tick population. Rth $<1$ indicates no biologically meaningful endemic equilibrium. ${ }^{116}$ The ability of recombinant antigen to detect anti-CCHFV IgG in sera of convalescent patients was analyzed by purified nucleoprotein (NP) based indirect ELISA. IgG antibodies were absent in healthy individuals but detected by plant-produced NP in all samples isolated from convalescent patients. ${ }^{117}$ Both cellular and humoral immunity are required to confer protection against $\mathrm{CCHF}$ after vaccination with MVA-GP vaccine. Animals who received both $\mathrm{CD} 3+\mathrm{T}$-cells and sera from immunised mice stayed alive for longer span than the animals who received either sera or T cells. ${ }^{118}$ A nurse and doctor acquired CCHF while treating CCHF patients. Health-care workers (HCWs) are at greater risk of $\mathrm{CCHF}$ due to personal communication with infected individuals. ${ }^{119}$

\section{DISCUSSION}

More than 80 articles were surveyed in this scoping review which were published between January 2016 to September 2016. CCHF is public health threat in almost 33 countries because of its endemic potential. Globally, 140 outbreaks have been documented since the discovery of CCHFV in 1967. The seropravelence in humans ranges from very low to $25 \% .20$

Based on genetic variation in small segment of RNA, $\mathrm{CCHFV}$ is actually clustered in 7 genotypes that are Asia 1 and 2, Europe 1 and 2, and Asia 1, 2 and 3. This genetic variation acts as a hindrance in development of CCHF vaccines. ${ }^{120}$ However, Ahmad et al. recently demonstrated the presence of some conserved epitopes present in all strains of CCHFV, the finding that may form the baseline for development of vaccine. Biosafety level 4 is recommended to deal with CCHFV because of its highly pathogenic nature. ${ }^{121}$

Enough light has been shed on virus internalisation mechanisms, molecular pathogenesis, viral replication cycle, and strategies to escape from host immune response. However, no approved vaccine available for treatment of the CCHF; but the recent development of MVA-GP has shown efficacy in mouse model by triggering both cellular and humoral immunity. ${ }^{118,122}$ Evidence suggests that oral ribavirin therapy is effective for $\mathrm{CCHF}$, but recent study regarded ribavirin as nonefficacious as it has not shown decrease in mortality rates. Therefore, its role is controversial. 123,124 Administration of anti-CCHF hyperimmunoglobulin may emerge as new therapeutic strategy, specifically in high risk patients; but the data regarding the effectiveness of this approach is still limited. ${ }^{125}$

\section{CONCLUSION}

The global emergence and re-emergence of CCHF highlight the importance of further groundwork to control the pathogen which is posing serious threats to human and animal health. Future research needs to particularly focus on development of countermeasures, treatment options, and immunocompetent CCHF disease models. In addition to lack of research, the data revealed major gap in the knowledge regarding practice of personal protective measures. Therefore, it is a high time to initiate educational campaigns, specifically for the people engaged in high risk activities such as veterinarians, agricultural workers, herders, and slaughterhouse workers.

\section{REFERENCES}

1. Fajs L, Humolli I, Saksida A, Knap N, Jelovšek M, Korva M, et al. Prevalence of Crimean-Congo hemorrhagic fever virus in healthy population, livestock and ticks in Kosovo. PLoS One 2014; 9:e110982.

2. World Health Organization, Crimean-Congo haemorrhagic fever; January 2013. http://www.who.int/mediacentre/factsheets/ fs208/en/.

3. Papa A, Maltezou HC, Tsiodras S, Dalla VG, Papadimitriou T, Pierroutsakos I, et al. A case of Crimean-Congo haemorrhagic fever in Greece, June 2008. Euro Surveill 2008; 13:18952.

4. Alam MM, Khurshid A, Sharif S, Shaukat S, Suleman RM, Angez $\mathrm{M}$, et al. Crimean-Congo hemorrhagic fever Asia-2 genotype, Pakistan. Emerg Infect Dis 2013; 19:1017-9.

5. Chinikar S, Ghiasi SM, Hewson R, Moradi M, Haeri A. Crimean-Congo hemorrhagic fever in Iran and neighboring countries. J Clin Virol 2010; 47:110-4.

6. Khurshid A, Hassan M, Alam MM, Aamir UB, Rehman L, Sharif S, et al. CCHF virus variants in Pakistan and Afghanistan: Emerging diversity and epidemiology. J Clin Virol 2015; 67: 25-30.

7. Donets MA, Chumakov MP, Korolev MB, Rubin SG. Physicochemical characteristics, morphology and morpho-genesis of virions of the causative agent of Crimean hemorrhagic fever. Intervirology 1977; 8:294-308.

8. Yi Wang, Sujit Dutta, Helen Karlberg, Stéphanie Devignot, Friedemann Weber, Quan Hao, et al., Structure of CrimeanCongo hemorrhagic fever virus nucleoprotein: superhelical homo-oligomers and the role of caspase-3 cleavage. J Virol 2012; 86:12294-303

9. Bergeron É, Zivcec M, Chakrabarti AK, Nichol ST, Albariño CG, Spiropoulou CF. Recovery of recombinant Crimean-Congo hemorrhagic fever virus reveals a function for non-structural glycoproteins cleavage by furin. PLoS Pathog 2015; 11: e1004879.

10. Flick R, Flick K, Feldmann H, Elgh F. Reverse genetics for Crimean-Congo hemorrhagic fever virus. J Virol 2003; 77: 5997-6006.

11. Erickson BR, Deyde V, Sanchez AJ, Vincent MJ, Nichol ST. $\mathrm{N}$-linked glycosylation of $\mathrm{Gn}$ (but not $\mathrm{Gc}$ ) is important for Crimean Congo hemorrhagic fever virus glycoprotein localization and transport. Virology 2007; 361:348-55. 
12. Xiao X, Feng Y, Zhu Z, Dimitrov DS. Identification of a putative Crimean-Congo hemorrhagic fever virus entry factor. Biochem Biophys Res Commun 2011; 411:253-8.

13. Bertolotti-Ciarlet A, Smith J, Strecker K, Paragas J, Altamura LA, McFalls JM, et al. Cellular localization and antigenic characterization of Crimean-Congo hemorrhagic fever virus glycoproteins. J Virol 2005; 79:6152-61.

14. Akuffo R, Brandful JA, Zayed A, Adjei A, Watany N, Fahmy NT, et al. Crimean-Congo hemorrhagic fever virus in livestock ticks and animal handler seroprevalence at an abattoir in Ghana. BMC Infect Dis 2016; 16:324.

15. Whitehouse CA. Crimean-Congo hemorrhagic fever. Antiviral Research 2004; 64:145-60.

16. Alam MM, Khurshid A, Sharif S, Shaukat S, Suleman RM, Angez M, et al. Genetic analysis and epidemiology of Crimean Congo hemorrhagic fever viruses in Baluchistan province of Pakistan. BMC Infect Dis 2013; 13:201.

17. Bodur H, Akinci E, Ongürü $P$, Carhan $A$, Uyar $Y$, Tanrici $A$, et al. Detection of Crimean-Congo hemorrhagic fever virus genome in saliva and urine. Int $J$ Infect Dis 2010; 14:e247-9.

18. Pshenichnaya NY, Sydenko IS, Klinovaya EP, Romanova EB, Zhuravlev AS. Possible sexual transmission of Crimean-Congo hemorrhagic fever. Int J Infect Dis 2016; 45:109-11.

19. Chinikar S, Ghiasi SM, Moradi M, Goya MM, Shirzadi MR, Zeinali $\mathrm{M}$, et al. Geographical distribution and surveillance of Crimean-Congo hemorrhagic fever in Iran. Vector Borne Zoonotic Dis 2010; 10:705-8.

20. Appannanavar SB, Mishra B. An update on Crimean-Congo hemorrhagic fever. J Glob Infect Dis 2011; 3:285-92.

21. Ergönül Ö. Crimean-Congo haemorrhagic fever. Lancet Infect Dis 2006; 6:203-14.

22. Papa A, Christova I, Papadimitriou E, Antoniadis A. CrimeanCongo hemorrhagic fever in Bulgaria. Emerg Infect Dis 2004; 10:1465-7.

23. Papa A, Bino S, Llagami A, Brahimaj B, Papadimitriou E, Pavlidou $V$, et al. Crimean-Congo hemorrhagic fever in Albania, 2001. Eur J Clin Microbiol Infect Dis 2002; 21:603-6.

24. Papa A, Papadimitriou E, Bozovic B, Antoniadis A. Genetic characterization of the M RNA segment of a Balkan CrimeanCongo hemorrhagic fever virus strain. J Med Virol 2005; 75:466-9.

25. Yashina L, Petrova I, Seregin S, Vyshemirskii O, Lvov D, Aristova $V$, et al. Genetic variability of Crimean-Congo haemorrhagic fever virus in Russia and Central Asia. J Gen Virol 2003; 84:1199-206.

26. Papa A, Bozovic B, Pavlidou V, Papadimitriou E, Pelemis M, Antoniadis A. Genetic detection and isolation of CrimeanCongo hemorrhagic fever virus, Kosovo, Yugoslavia. Emerg Infect Dis 2002; 8:852-4.

27. Seregin SV, Samokhvalov EI, Petrova ID, Vyshemirskii OI, Samokhvalova EG, Lvov DK, et al. Genetic characterization of the M RNA segment of Crimean-Congo hemorrhagic fever virus strains isolated in Russia and Tajikistan. Virus Genes 2004; 28:187-93

28. Shayan S, Bokaean M, Shahrivar MR, Chinikar S. CrimeanCongo hemorrhagic fever. Lab Med 2015; 46:180-9.

29. Hewson R, Gmyl A, Gmyl L, Smirnova SE, Karganova G, Jamil B, et al. Evidence of segment reassortment in Crimean-Congo haemorrhagic fever virus. J Gen Virol 2004; 85:3059-70.
30. Athar MN, Baqai HZ, Ahmad M, Khalid MA, Bashir N, Ahmad AM, et al. Crimean-Congo hemorrhagic fever outbreak in Rawalpindi, Pakistan, February 2002. Am J Trop Med Hyg 2003; 69:284-7.

31. Akinci E, Bodur H, Leblebicioglu H. Pathogenesis of CrimeanCongo hemorrhagic fever. Vector Borne Zoonotic Dis 2013; 13:429-37.

32. Fisman DN. Hemophagocytic syndromes and infection. Emerging Infect Dis 2000; 6:601.

33. Ergonul O, Tuncbilek S, Baykam N, Celikbas A, Dokuzoguz B. Evaluation of serum levels of interleukin (IL)-6, IL-10, and tumor necrosis factor- $\alpha$ in patients with Crimean-Congo hemorrhagic fever. J Infect Dis 2006; 193:941-4.

34. Connolly-Andersen AM, Douagi I, Kraus AA, Mirazimi A. Crimean-Congo hemorrhagic fever virus infects human monocyte-derived dendritic cells. Virol 2009; 390:157-62.

35. Bodur H, Akinci E, Öngürü $P$, Uyar $Y$, Bastürk B, Gözel MG, et al. Evidence of vascular endothelial damage in CrimeanCongo hemorrhagic fever. IJID 2010; 14:e704-7.

36. Bente DA, Alimonti JB, Shieh W-J, Camus G, Ströher U, Zaki S, et al. Pathogenesis and immune response of Crimean-Congo hemorrhagic fever virus in a STAT-1 knockout mouse model. J Virol 2010; 84:11089-100.

37. Rodrigues R, Paranhos-Baccalà G, Vernet G, Peyrefitte CN. Crimean-Congo hemorrhagic fever virus-infected hepatocytes induce ER-stress and apoptosis crosstalk. PLoS One 2012; 7:e29712.

38. Kilinc C, Gückan R, Capraz M, Varol K, Zengin E, Mengeloglu Z, et al. Examination of the specific clinical symptoms and laboratory findings of Crimean-Congo hemorrhagic fever. Vector Borne Zoonotic Dis 2016; 53:162.

39. Burnett M. Crimean-Congo Hemorrhagic Fever. J Spec Oper Med 2015; 15:96-8.

40. Vashakidze E, Mikadze I. Epidemiology, clinical and laboratory features of Crimean-Congo hemorrhagic fever in Georgia. Georgian Med News 2015; 247:54-8.

41. Bente DA, Forrester NL, Watts DM, McAuley AJ, Whitehouse CA, Bray M. Crimean-Congo hemorrhagic fever: History, epidemiology, pathogenesis, clinical syndrome and genetic diversity. Antiviral Res 2013; 100:159-89.

42. Zahraei B, Hashemzadeh MS, NajarasI M, Zahiriyeganeh S, Tat M, Metanat M, et al. Novel, in-house, SYBR green based one-step rRT-PCR: Rapid and accurate diagnosis of crimeancongo hemorrhagic fever virus in suspected patients from Iran. Jundishapur J Microbiol 2016; 9:e29246.

43. Tezer H, Ozkaya-Parlakay A, Gulhan B, Kanik-Yuksek S. Ribavirin use in pediatric patients with Crimean-Congo hemorrhagic fever: Is it really necessary? Brazilian J Infect Dis 2016; 20:222-3.

44. Ferraris $\mathrm{O}$, Moroso $\mathrm{M}$, Pernet $\mathrm{O}$, Emonet $\mathrm{S}$, Rembert $\mathrm{AF}$, Paranhos-Baccalà $\mathrm{G}$, et al. Evaluation of Crimean-Congo hemorrhagic fever virus in vitro inhibition by chloroquine and chlorpromazine, two FDA approved molecules. Antiviral Res 2015; 118:75-81.

45. Andersson I, Bladh L, Mousavi-Jazi M, Magnusson KE, Lundkvist $\AA$, Haller $O$, et al. Human MxA protein inhibits the replication of Crimean-Congo hemorrhagic fever virus. J Virol 2004; 78:4323-9. 
46. Spik K, Shurtleff A, McElroy AK, Guttieri MC, Hooper JW, Schmaljohn C. Immunogenicity of combination DNA vaccines for Rift Valley fever virus, tick-borne encephalitis virus, Hantaan virus, and Crimean-Congo hemorrhagic fever virus. Vaccine 2006; 24:4657-66.

47. Lani R, Moghaddam E, Haghani A, Chang LY, AbuBakar S, Zandi K. Tick-borne viruses: A review from the perspective of therapeutic approaches. Ticks Tick Borne Dis 2014; 5:457-65.

48. Messina JP, Pigott DM, Golding N, Duda KA, Brownstein JS, Weiss DJ, et al. The global distribution of Crimean-Congo hemorrhagic fever. Trans $R$ Soc Trop Med Hyg 2015; 109: 503-13.

49. Ministry of National Health Services, National Institute of Health, Islamabad, Government of Pakistan. http://www.nih.org.pk/ files/Newsletter/Seasonal\%20Awareness $\% 20$ and\%20Alert\%2 OLetter\%20(SAAL)\%2031st\%20lssue.pdf.

50. WHO, Crimean-Congo haemorrhagic fever in Pakistan. http:// www.emro.who.int/surveillance-forecasting-response/ surveillance-news/cchf-july-2014.html.

51. Khan V, Zala D, Joshi K. Occurrence of Hyalomma, (Acari: Ixodidae) Koch, 1844 on domestic animal in the Union Territory of Dadra \& Nagar Haveli, Indian. J Parasit Dis 2016; 40:543-5.

52. Leblebicioglu $H$, Ozaras $R$, Fletcher TE, Beeching NJ. Crimean-Congo haemorrhagic fever in travellers: A systematic review. Travel Med Infect Dis 2016; 14:73-80.

53. Wangchuk S, Pelden S, Dorji T, Tenzin S, Thapa B, Zangmo S, et al. Crimean-Congo hemorrhagic fever virus IgG in goats, Bhutan. Emerg Infect Dis 2016; 22:919.

54. Palomar AM, Portillo A, Mazuelas D, Roncero L, Arizaga J, Crespo A, et al. Molecular analysis of Crimean-Congo hemorrhagic fever virus and Rickettsia in Hyalomma marginatum ticks removed from patients (Spain) and birds (Spain and Morocco), 2009-2015. Ticks Tick Borne Dis 2016; 7:983-7.

55. England ME, Phipps P, Medlock JM, Atkinson PM, Atkinson B, Hewson $\mathrm{R}$, et al. Hyalomma ticks on northward migrating birds in southern Spain: Implications for the risk of entry of CrimeanCongo haemorrhagic fever virus to Great Britain. $J$ Vector Ecol 2016; 41:128-34.

56. Müller MA, Devignot S, Lattwein E, Corman VM, Maganga GD, Gloza-Rausch $F$, et al. Evidence for widespread infection of African bats with Crimean-Congo hemorrhagic fever-like viruses. Sci Rep 2016; 6:26637.

57. Salehi-Vaziri M, Baniasadi V, Jalali T, Mirghiasi SM, AzadManjiri S, Zarandi R, et al. The first fatal case of CrimeanCongo hemorrhagic fever caused by the AP92-like strain of the Crimean-Congo hemorrhagic fever virus. Jpn J Infect Dis 2016; 69:344-6.

58. Schuster I, Mertens M, Mrenoshki S, Staubach C, Mertens C, Brüning $\mathrm{F}$, et al. Sheep and goats as indicator animals for the circulation of CCHFV in the environment. Exp Appl Acarol 2016; 68:337-46.

59. Marc M, Isolde S, A. SM, Zati V, Zdenek H, Esin G, et al. Crimean-Congo hemorrhagic fever virus in Bulgaria and Turkey. Vector Borne Zoonotic Dis 2016; 16:619-23.

60. Fazlalipour M, Baniasadi V, Mirghiasi SM, Jalali T, Khakifirouz S, Azad-Manjiri $\mathrm{S}$, et al. Crimean-Congo hemorrhagic fever due to consumption of raw meat: Case reports from East-North of Iran. Jpn J Inf Dis 2016; 69:270-1.
61. Spengler JR, Bergeron E, Rollin PE. Seroepidemiological Studies of Crimean-Congo hemorrhagic fever virus in domestic and wild animals. PLoS Negl Trop Dis 2016; 10:e0004210.

62. Sharififard M, Alavi SM, Salmanzadeh S, Safdari F, Kamali A. Epidemiological survey of Crimean-Congo hemorrhagic fever (CCHF), a fatal infectious disease in Khuzestan province, Southwest Iran, during 1999 - 2015. Jundishapur J Microbiol 2016; 9:e30883-e.

63. Dreshaj S, Ahmeti S, Ramadani N, Dreshaj G, Humolli I, Dedushaj I. Current situation of Crimean-Congo hemorrhagic fever in Southeastern Europe and neighboring countries: A public health risk for the European Union? Travel Med Infect Dis 2016; 14:81-91.

64. Vial L, Stachurski F, Leblond A, Huber K, Vourc'h G, RenéMartellet $\mathrm{M}$, et al. Strong evidence for the presence of the tick Hyalomma marginatum Koch, 1844 in southern continental France. Ticks and Tick-borne Dis 2016; 7:1162-7.

65. Horton CK, Nermeen TF, Noha W, Alia Z, Abro M, Abdo AA, et al. Crimean-Congo hemorrhagic fever virus and alkhurma virus in ticks in Djibouti. Vector-Borne Zoonotic Dis 2016; 16:680-2.

66. Gazi H, Nuri Ö, Talat E, Gonca A, Galip K, Semra K, et al. Seroprevalence of West Nile virus, Crimean-Congo hemorrhagic fever virus, Francisella tularensis and Borrelia burgdorferi in rural population of Manisa, Western Turkey. $J$ Vector-borne Dis 2016; 53:112.

67. Greiner AL, Mamuchishvili N, Kakutia N, Stauffer K, Geleishvili M, Chitadze $\mathrm{N}$, et al. Crimean-Congo hemorrhagic fever knowledge, attitudes, practices, risk factors, and seroprevalence in rural Georgian villages with known transmission in 2014. PLOS One 2016; 11:e0158049.

68. Champour M, Chinikar S, Mohammadi G, Razmi G, Mostafavi E, Shah-Hosseini $\mathrm{N}$, et al. Crimean-Congo hemorrhagic fever in the one-humped camel (camelus dromedarius) in East and Northeast of Iran. J Arthropod-borne Dis 2016; 10:168-77.

69. Qidwai W. Crimean-Congo haemorrhagic fever: An emerging public healthcare challenge in Pakistan. J Coll Physicians Surg Pak 2016; 26:81-2.

70. Karakeçili F, Çikman A, Akin H, Gülhan B, Özçiçek A. A case of brucellosis and Crimean-Congo hemorrhagic fever coinfection in an endemic area. Mikrobiyol Bul 2016; 50:322-7.

71. Wasfi F, Dowall S, Ghabbari T, Bosworth A, Chakroun M, Varghese A, et al. Sero-epidemiological survey of CrimeanCongo hemorrhagic fever virus in Tunisia. Parasite 2016; 23:10.

72. Bayram Y, Parlak M, Özkaçmaz A, Çikman A, Güdücüoglu H, Kiliç $S$, et al. Seroprevalence of Crimean-Congo hemorrhagic fever in Turkey's Van Province. Jpn J of Infect Dis 2017; 70:65-8.

73. Farooq MG, Cyril B, Habiburrahman R, Rohullah Z, Stefan F. Prevalence of zoonotic and vector-borne infections among Afghan national army recruits in Afghanistan. Vector-Borne Zoonotic Dis 2016; 16:501-6.

74. Hasanoglu I, Guner R, Carhan A, Kocak Tufan Z, YagciCaglayik D, Guven T, et al. Crucial parameter of the outcome in Crimean-Congo hemorrhagic fever: Viral load. $J$ Clin Virol 2016; 75:42-6.

75. Leblebicioglu H, Ozaras R, Irmak H, Sencan I. Crimean-Congo hemorrhagic fever in Turkey: Current status and future challenges. Antiviral Res 2016; 126:21-34. 
76. Safronetz D, Sacko M, Sogoba N, Rosenke K, Martellaro C, Traoré S, et al. Vectorborne infections, Mali. Emerging Infect Dis 2016; 22:340-2.

77. Aytekin C, Merve A, Baris G, Faruk K, Arif KO, Adalet O, et al. Seroprevalence of Crimean-Congo hemorrhagic fever virus in Erzincan province, Turkey, relationship with geographic features and risk factors. Vector-Borne Zoonotic Dis 2016; 16:199-204

78. Yilmaz G, Yilmaz $H$, Arslan $M$, Kostakoglu U, Mentese A, Karahan SC, et al. The prognostic significance of serum TGF- $\beta 1$ levels in patients with Crimean-Congo hemorrhagic fever. J Med Virol 2017; 89:413-6.

79. Yilmaz H, Yilmaz G, Mentese A, Kostakoglu U, Karahan SC, Köksal I. Prognostic impact of platelet distribution width in patients with Crimean-Congo hemorrhagic fever. J Med Virol 2016; 88:1862-6.

80. Akinci E, Bodur H, Sunbul M, Leblebicioglu H. Prognostic factors, pathophysiology and novel biomarkers in CrimeanCongo hemorrhagic fever. Antiviral Res 2016; 132:233-43.

81. Rus KR, Fajs L, Korva M, Avšic-Županc T. HMGB1 is a potential biomarker for severe viral hemorrhagic fevers. PLOS Negl Trop Dis 2016; 10:e0004804.

82. Tufan ZK, Hasanoglu I, Kolgelier S, Alisik M, Ergin M, Yilmaz GR, et al. A retrospective controlled study of thiol disulfide homeostasis as a novel marker in Crimean Congo hemorrhagic fever. Redox Rep 2017; 22:241-5.

83. Molinas A, Mirazimi A, Holm A, Loitto VM, Magnusson KE, Vikström E. Protective role of host aquaporin 6 against Hazara virus, a model for Crimean-Congo hemorrhagic fever virus infection. FEMS Microbiol Lett 2016; 363:fnw058.

84. Kaya S, Aksoy F, Kenç NN, Eroglu A, Köksal I. The importance of supportive care with tranexamic acid in Crimean-Congo hemorrhagic fever. Chemotherapy 2016; 61:148-51.

85. Bakir M, Engin A, Kuskucu MA, Bakir S, Gündag O, Midilli K. Relationship of plasma cell-free DNA level with mortality and prognosis in patients with Crimean-Congo hemorrhagic fever. J Med Virol 2016; 88:1152-8.

86. Leblebicioglu $H$, Sunbul $M$, Bodur $H$, Ozaras R, Barut $S$, Buyuktuna SA, et al. Discharge criteria for Crimean-Congo haemorrhagic fever in endemic areas. J Infect 2016; 72:500-1.

87. Aksoy O, Parlak E, Parlak M, Aksoy H. Serum $\beta$-defensin-2 levels and their relationship with the clinical course and prognosis in patients with Crimean-Congo hemorrhagic fever. Med Princ Pract 2016; 25:163-8.

88. Papa A, Tsergouli K, Çaglayik DY, Bino S, Como N, Uyar Y, et al. Cytokines as biomarkers of Crimean-Congo hemorrhagic fever. J Med Virol 2016; 88:21-7.

89. Bastug A, Kayaaslan B, Kazancioglu S, Aslaner H, But A, Akinci E, et al. Crimean-Congo hemorrhagic fever: Prognostic factors and the association of leukocyte counts with mortality. Jpn J Infect Dis 2016; 69:51-5.

90. Kazancioglu S, Akinci E, Bastug A, Kayaaslan B, But A, Aslaner $\mathrm{H}$, et al. Does the course of laboratory parameters help us to predict the outcome of CCHF? Turkish J Med Sci 2016; 46:328-34.

91. Eren SH, Zengin S, Büyüktuna SA, Gözel MG. Clinical severity in forecasting platelet to lymphocyte ratio in Crimean-Congo hemorrhagic fever patients. J Med Microbiol 2016; 65:1100-4.
92. Aktas T, Aktas F, Özmen Z, Kaya T. Does Crimean-Congo hemorrhagic fever cause a vasculitic reaction with pulmonary artery enlargement and acute pulmonary hypertension? Lung 2016; 194:807-12.

93. Tanyel E, Sunbul M, Fletcher T, Leblebicioglu H. A case of endocarditis mimicking Crimean-Congo haemorrhagic fever. Trop Doct 2017; 47:71-2.

94. Kleib AS, Salihy SM, Ghaber SM, Sidiel BW, Sidiya KC, Bettar ES. Crimean-Congo hemorrhagic fever with acute subdural hematoma, Mauritania, 2012. Emerging Infect Dis 2016; 22: 1305.

95. Demir ZC, Bastug A, Bodur H, Ergunay K, Ozkul A. MicroRNA expression profiles in patients with acute Crimean-Congo hemorrhagic fever reveal possible adjustments to cellular pathways. J Med Virol 2017; 89: 417-22.

96. Surtees R, Dowall SD, Shaw A, Armstrong S, Hewson R, Carroll MW, et al. Heat shock protein 70 family members interact with Crimean-Congo hemorrhagic fever virus and Hazara virus nucleocapsid proteins and perform a functional role in the Nairovirus replication cycle. $J$ Virol 2016; 90: 9305-16.

97. Deaton M, Dzimianski J, Daczkowski C, Whitney G, Mank N, Parham $\mathrm{M}$, et al. Biochemical and structural insights into nairoviral delSGylases preference for interferon-stimulatedgene-product 15 originating from certain species. $J$ Virol 2016; 90:8314-27.

98. Guler N, Eroglu C, Yilmaz H, Karadag A, Alacam H, Sunbul $\mathrm{M}$, et al. Apoptosis-related gene expression in an adult cohort with Crimean-Congo hemorrhagic fever. PloS One 2016; 11: e0157247.

99. Zivcec M, Scholte F, Spiropoulou C, Spengler J, Bergeron É. Molecular insights into Crimean-Congo hemorrhagic fever virus. Viruses 2016; 8:106.

100. Chinikar S, Shah-Hosseini N, Bouzari S, Shokrgozar MA, Mostafavi $\mathrm{E}$, Jalali $\mathrm{T}$, et al. Assessment of recombination in the S-segment genome of Crimean-Congo hemorrhagic fever virus in Iran. J Arthropod-borne Dis 2016; 10:12.

101. Tipu HN. Immunoinformatic analysis of Crimean-Congo hemorrhagic fever virus glycoproteins and epitope prediction for synthetic peptide vaccine. J Coll Physicians Surg Pak 2016; 26:108-12.

102. Farhadpour F, Telmadarraiy Z, Chinikar S, Akbarzadeh K, Moemenbellah-Fard M, Faghihi F, et al. Molecular detection of Crimean-Congo haemorrhagic fever virus in ticks collected from infested livestock populations in a new endemic area, south of Iran. Trop Med Int Health 2016; 21:340-7.

103. Yadav PD, Raut CG, Patil DY, Majumdar TD, Mourya DT. Crimean-Congo hemorrhagic fever: Current scenario in India. Proc Natl Acad Sci India Sect B Biol Sci 2014; 84:9-18.

104. Chitimia-Dobler L, Nava S, Bestehorn M, Dobler G, Wölfel S. First detection of hyalomma rufipes in Germany. Ticks Tickborne Dis 2016; 7:1135-8.

105. Biglari P, Chinikar S, Belqeiszadeh H, Telmadarraiy Z, Mostafavi E, Ghaffari M, et al. Phylogeny of tick-derived Crimean-Congo hemorrhagic fever virus strains in Iran. Ticks Tick-borne Dis 2016; 7:1216-21.

106. Panayotova E, Papa A, Trifonova I, Christova I. CrimeanCongo hemorrhagic fever virus lineages Europe 1 and Europe 2 in Bulgarian ticks. Ticks Tick-borne Dis 2016; 7:1024-8. 
107. Chinikar S, Bouzari S, Shokrgozar MA, Mostafavi E, Jalali T, Khakifirouz S, et al. Genetic diversity of Crimean-Congo hemorrhagic fever virus strains from Iran. J Arthropod-borne Dis 2016; 10:127.

108. Shimada S, Aoki K, Nabeshima T, Fuxun Y, Kurosaki Y, Shiogama K, et al. Tofla virus: A newly identified Nairovirus of the Crimean-Congo hemorrhagic fever group isolated from ticks in Japan. Sci Rep 2016; 6:20213.

109. Kautman M, Tiar G, Papa A, Široký P. AP92-like CrimeanCongo hemorrhagic fever virus in hyalomma aegyptium ticks, Algeria. Emerging Infect Dis 2016; 22:354-6.

110. Demirpençe Ö, Dogan HO, Ersan S, Sahin M, Sahin H, Bakir M. Presepsin levels of patients with Crimean-Congo hemorrhagic fever. Jpn J Infect Dis 2016; 69:505-9.

111. Engin $\mathrm{A}$, Arslan $\mathrm{S}$, Özbilüm N, Bakir M. Is there any relationship between toll-like receptor $3 \mathrm{c} .1377 \mathrm{C} / \mathrm{T}$ and $-7 \mathrm{C} / \mathrm{A}$ polymorphisms and susceptibility to Crimean-Congo hemorrhagic fever? J Med Virol 2016; 88:1690-6.

112. Elaldi N, Yilmaz M, Bagci B, Yelkovan I, Bagci G, Gozel MG, et al. Relationship between IFNA1, IFNA5, IFNA10, and IFNA17 gene polymorphisms and Crimean-Congo hemorrhagic fever prognosis in a Turkish population range. $J$ Med Virol 2016; 88:1159-67.

113. Suda Y, Fukushi S, Tani H, Murakami S, Saijo M, Horimoto $\mathrm{T}$, et al. Analysis of the entry mechanism of Crimean-Congo hemorrhagic fever virus, using a vesicular stomatitis virus pseudotyping system. Arch Virol 2016; 161:1447-54.

114. Altay FA, Elaldi N, Sentürk GÇ, Altin N, Gözel MG, Albayrak $\mathrm{Y}$, et al. Serum sTREM-1 level is quite higher in CrimeanCongo Hemorrhagic Fever, a viral infection. J Med Virol 2016; 88: 1473-8.

115. Bhaskar B, Karlberg H, Mirazimi A, Tan YJ. The nonstructural protein of crimean-congo hemorrhagic fever virus disrupts the mitochondrial membrane potential and induces apoptosis. J Biol Chem 2016; 291:582-92.

116. Switkes J, Nannyonga B, Mugisha JYT, Nakakawa J. A mathematical model for Crimean-Congo haemorrhagic fever: tick-borne dynamics with conferred host immunity. J Biol Dyn 2016; 10:59-70.
117. Atkinson R, Burt F, Rybicki EP, Meyers AE. Plant-produced Crimean-Congo haemorrhagic fever virus nucleoprotein for use in indirect ELISA. J Virol Methods 2016; 236:170-7.

118. Dowall SD, Graham VA, Rayner E, Hunter L, Watson R, Taylor I, et al. Protective effects of a modified vaccinia Ankara-based vaccine candidate against Crimean-Congo haemorrhagic fever virus require both cellular and humoral responses. PLOS One 2016; 11:e0156637.

119. Yildirmak T, Tulek N, Bulut C. Crimean-Congo haemorrhagic fever: Transmission to visitors and healthcare workers. Infect 2016:1-3.

120. Mild M, Simon M, Albert J, Mirazimi A. Towards an understanding of the migration of Crimean-Congo hemorrhagic fever virus. J Gen Virol 2010; 91:199-207.

121. Ahmed AA, McFalls JM, Hoffmann C, Filone CM, Stewart $\mathrm{SM}$, Paragas $\mathrm{J}$, et al. Presence of broadly reactive and group-specific neutralizing epitopes on newly described isolates of Crimean-Congo hemorrhagic fever virus. $J$ General Virol 2005; 86:3327-36.

122. Buttigieg KR, Dowall SD, Findlay-Wilson S, Miloszewska A, Rayner E, Hewson $\mathrm{R}$, et al. A novel vaccine against Crimean-Congo haemorrhagic fever protects $100 \%$ of animals against lethal challenge in a mouse model. PloS One 2014; 9:e91516.

123. Ceylan B, Calica A, Ak O, Akkoyunlu Y, Turhan V. Ribavirin is not effective against Crimean-Congo hemorrhagic fever: Observations from the Turkish experience. IJID 2013; 17: e799-e801.

124. Ergönül Ö, Çelikbas A, Dokuzoguz B, Eren S, Baykam N, Esener $\mathrm{H}$. Characteristics of patients with Crimean-Congo hemorrhagic fever in a recent outbreak in Turkey and impact of oral ribavirin therapy. Clin Infect Diseases 2004; 39:284-7.

125. Kubar A, Haciomeroglu M, Ozkul A, Bagriacik U, Akinci E, Sener $\mathrm{K}$, et al. Prompt administration of Crimean-Congo hemorrhagic fever (CCHF) virus hyperimmunoglobulin in patients diagnosed with CCHF and viral load monitorization by reverse transcriptase-PCR. $J$ Infect Dis 2011; 64: $439-43$ 